\title{
Колбанов В.В.
}

\section{Рефлексии молодых врачей на темы здоровья, образа жизни и медицины}

Первый Санкт-Петербургский государственный медицинский университет имени академика И. П. Павлова (Россия, Санкт-Петербург)

doi: $10.18411 / \mathrm{lj}-28-02-2018-61$

idsp: 000001:lj-28-02-2018-61

\section{Аннотация}

Для изучения профессионального мировоззрения и отношения молодых врачей к своему здоровью, образу жизни разработана специальная анкета. В исследовании участвовали 164 врача (114 женщин и 50 мужчин) в возрасте до 30 лет. Большинство респондентов высоко оценивает своё здоровье и стрессоустойчивость, но их образ жизни не может считаться благоприятным для здоровья. Выявлены неспособность большинства респондентов отказаться от какого-либо фактора риска и неумение пользоваться факторами, полезными для здоровья. Знания о здоровье и здоровом образе жизни, получаемые в медицинском вузе, неполноценны и должны быть компенсированы за счёт введения в образовательный процесс специального учебного предмета.

Ключевые слова: врач, здоровье, образ жизни, дефиниция, анкета, самооценка, компетентность.

\section{Abstract}

The special questionnaire for the investigation of physicians' relation to their health, life style and professional competence was prepared. Participants of the investigation were 164 young doctors (114 women and 50 men) aged till 30 . The majority of respondents have a high valuation of their health and stress-resistance but their life style can't be named favourable for a health. Inability of respondents' majority to reject any risk-factors and to use rationally some useful for a health factors were revealed. Knowledge about health and healthy life style acquired in medical institutions of higher education is imperfect and must be compensate by special educational subject.

Keywords: physician, health, healthy life style, definition, questionnaire, self-valuation, competence.

\section{Введение}

Первая попытка создать дефиницию здоровья без её противопоставления понятию болезни, предпринятая Всемирной организацией здравоохранения в 1968 году, была вполне логична как преодоление антитезы части и целого [7]. Но рассмотрение болезни как частного варианта здоровья до сих пор, полвека спустя, не добавило ничего позитивного к пониманию феномена здоровья. Это оставалось бы на уровне отвлечённых дискуссий, если бы отсутствие конкретного определения здоровья не тормозило развитие таких направлений как диспансеризация, профилактика, здоровый образ жизни, физическое воспитание [5, с. 64]. Очевидно, преодоление этой инертности необходимо начинать в системе профессиональной подготовки и повышения квалификации врачей, для чего, в первую очередь, необходимо выявить недостающие звенья в компетентности современных выпускников медицинских вузов. Это явилось целью данного исследования.

\section{Методика исследования}

Для ознакомления с профессиональным мировоззрением молодых врачей, их самооценкой собственного здоровья и образа жизни разработана специальная анкета, содержащая две группы вопросов. Первая часть анкеты содержала 10 вопросов, касающихся здоровья и образа жизни по десятибалльной шкале самооценки. Вторая часть 
предлагала бинарный выбор (да - нет) ответов на 13 вопросов, имеющих отношение к теории и практике профессиональной деятельности.

В добровольном анонимном анкетировании приняли участие молодые врачи (возраст - не старше 30 лет), 114 женщин и 50 мужчин, обучающиеся в клинической ординатуре. Здесь учтено участие только тех врачей, чьи анкеты содержали ответы на все вопросы.

\section{Результаты и обсуждение}

Ответы на первую группу вопросов, ранжированные по десятибалльной системе, не выявили чётко выраженной моды (наиболее вероятных значений) в обеих гендерных гистограммах распределения, что позволило распределить ответы по трём уровням. К высокому уровню были отнесены ответы, набравшие 8-10 баллов, к низкому - 1-3 балла, а остальные - к среднему. Для сопоставления результатов опроса мужчин и женщин количество ответов было выражено в процентах от общего количества каждой гендерной группы.

Самооценка здоровья и психосоматического статуса респондентов мужского и женского пола представлена в таблице 1.

Таблий 1.

Здоровье и психосоматический статус

\begin{tabular}{|c|c|c|c|c|c|c|}
\hline \multirow{3}{*}{ Показатели } & \multicolumn{6}{|c|}{ Распределение по уровням оценки,\% } \\
\hline & \multicolumn{2}{|c|}{ Высокий } & \multicolumn{2}{|c|}{ Средний } & \multicolumn{2}{|c|}{ Низкий } \\
\hline & $\mathrm{M}$ & Ж & $\mathrm{M}$ & Ж & $\mathrm{M}$ & Ж \\
\hline Здоровье & 64 & 67,5 & 34 & 31,6 & 2 & 0,9 \\
\hline Стрессоустойчивость & 80 & 51,8 & 20 & 41,2 & 0 & 7,0 \\
\hline Качество сна & 24 & 25,4 & 54 & 61,4 & 22 & 13,2 \\
\hline
\end{tabular}

В показателях самооценки достоверных различий между гендерными группами не выявлено. Низкие уровни оценки здоровья в обеих группах можно отнести к статистической погрешности. Преобладание высокой устойчивости к стрессорам у мужчин вряд ли можно объяснить неврологическими предпосылками, но в большей мере - особенностями социального менталитета, что подтверждается более придирчивым отношением к качеству сна по сравнению с женщинами. Несомненно, отсутствие корреляции между двумя психосоматическими показателями и их отношением к субъективной оценке здоровья - не повод для объективной медицинской оценки.

Более внимательного отношения исследователя заслуживают показатели образа жизни респондентов. С середины XX века и поныне в популярной медицинской литературе по вопросам здорового образа жизни (ЗОЖ) главное внимание уделяется преодолению вредных форм поведения, сопряжённых с риском развития хронических болезней. Эти привычки получили название факторов риска. Большинству населения эти факторы хорошо известны с детского возраста, но, несмотря на достаточно полную осведомлённость и обилие профилактических программ, они стойко удерживаются в быту в виде вредных привычек (курение, употребление алкоголя и психоактивных веществ, ПАВ). Подверженность действию этих факторов и успешность их избегания в поведении обследованных врачей представлены в таблице 2.

Таблииа 2.

Уровни предупреждения или преодоления вредных привычек

\begin{tabular}{|c|c|c|c|c|c|c|}
\hline \multirow{2}{*}{ Показатели } & \multicolumn{6}{|c|}{ Распределение по уровням оценки, \% } \\
\cline { 2 - 8 } & \multicolumn{2}{|c|}{ Высокий } & \multicolumn{2}{|c|}{ Средний } & \multicolumn{2}{c|}{ Низкий } \\
\cline { 2 - 8 } & $\mathrm{M}$ & Ж & М & Ж & 12 & 14,9 \\
\hline Отказ от курения & 82 & 80,7 & 6 & 21,9 & 14 & 7,0 \\
\hline Отказ от алкоголя & 52 & 71,1 & 28 & 1,8 & 4 & 7,0 \\
\hline Отказ от ПАВ & 92 & 91,2 & 4 & &
\end{tabular}


Распределение ответов по уровням успешности предупреждения названных факторов риска, мягко выражаясь, не внушает оптимизма в решении профилактических задач, поскольку значительное количество врачей не способны преодолеть собственные гедонические пристрастия. Настораживает, что поведение женщин мало отличается от поведения мужчин, а средний уровень готовности к отказу от употребления алкоголя значительно превышает средний уровень воздержания от курения и употребления психоактивных веществ. В сущности, это группа людей, не способная преодолеть силу псевдотрадиций, распространённых в современном социуме. Создаётся впечатление, что в системе медицинского образования проблема ЗОЖ не нашла должной реализации.

Вторая составляющая ЗОЖ - это результат воспитательной работы в области формирования позитивного отношения к своему здоровью. В таблице 3 представлено отношение респондентов к созданию благоприятных для здоровья условий жизни и к активным формам поведения, получившим общее название факторов устойчивости [3].

таблийа 3.

Особенности образа жизни молодых врачей

\begin{tabular}{|c|c|c|c|c|c|c|}
\hline \multirow{2}{*}{ Показатели } & \multicolumn{5}{|c|}{ Распределение по уровням оценки, } \\
\cline { 2 - 8 } & \multicolumn{2}{|c|}{ Высокий } & \multicolumn{2}{|c|}{ Средний } & \multicolumn{2}{c|}{ Низкий } \\
\cline { 2 - 8 } & $\mathrm{M}$ & Ж & $\mathrm{M}$ & Ж & \multicolumn{2}{|c|}{ Ж } \\
\hline Пищевой режим & 38 & 49,1 & 50 & 45,6 & 12 & 5,3 \\
\hline Жилищные условия & 70 & 75,4 & 30 & 20,2 & 0 & 4,4 \\
\hline Двигательная активность & 60 & 53,5 & 38 & 43,9 & 3 & 2,6 \\
\hline Закаливание & 18 & 15,8 & 42 & 42,1 & 40 & 42,1 \\
\hline
\end{tabular}

Оценка мужчинами и женщинами собственного пищевого режима (регулярность и адекватность питания), хотя и не имеет статистически значимых различий, но свидетельствует о более ответственном отношении женщин к этой характеристике образа жизни. В обеих группах отношение к жилищным условиям можно назвать вполне благополучным, по крайней мере, не препятствующим ведению ЗОЖ, но менее скрупулёзным в мужской среде. Оптимистичную оценку своей двигательной активности примем скорее как желаемую, нежели реальную, если сравнить с аналогичными показателями студентов, имеющих более благоприятные условия для занятий физкультурой. Но отношение к закаливающим процедурам можно признать неблагополучным в одинаковой мере среди мужчин и женщин, что явилось результатом нерационального физического воспитания в студенческие годы. Коррекция поведения молодых специалистов с учётом выявленных проблем даже на уровне субъективной самооценки - предмет дальнейших исследований.

Особого рассмотрения требуют ответы респондентов, отражающие сформированность профессионального отношения к ключевым понятиям медицины. Эти ответы представлены в таблице 4. Результаты, представленные в таблице, не дают единого представления ни по одному из поставленных вопросов даже в тех случаях, когда, казалось бы, нет повода для сомнений.

Таблица 4.

Суждения молодых врачей о фундаментальных проблемах медицинской науки и путях их практических решений

\begin{tabular}{|c|r|c|c|}
\hline № & Дискуссионные вопросы & \multicolumn{2}{c|}{ Ответы, \% } \\
\cline { 3 - 4 } п/п & да & нет \\
\hline & Целесообразно ли использовать в науке термины, не имеющие однозначной & 19,6 & 80,4 \\
1 & трактовки и строгого научного определения? & 41,2 & 58,8 \\
\hline 2 & Здоровье - это состояние организма? & 38,4 & 61,6 \\
\hline 3 & 3доровье - это процесс в организме? & 37,3 & 62,7 \\
\hline 4 & Здоровье - это свойство организма? & 75,9 & 24,1 \\
\hline 5 & 3доровье - это ресурс организма? & & \\
\hline
\end{tabular}




\begin{tabular}{|c|c|c|c|}
6 & $\begin{array}{c}\text { Допустимо ли при оценке здоровья или образа жизни использование термина } \\
\text { «духовное» вместо «нравственное»? }\end{array}$ & 39,0 & 61,0 \\
\hline 7 & \begin{tabular}{|} 
Правомочна ли парциальная оценка здоровья: физическое, психическое, здоровье \\
печени, здоровье позвоночника?
\end{tabular} & 47,5 & 52,5 \\
\hline 8 & Можно ли использовать как синонимы «болезнь» и «заболевание»? & 48,6 & 51,4 \\
\hline 9 & Считаете ли вредной рекламу лекарств и медтехники в СМИ? & 68,9 & 31,1 \\
\hline 10 & Являются ли медицинские знания решающим фактором в выборе здорового \\
образа жизни? & 44,6 & 55,4 \\
\hline 11 & Нужны ли уроки здоровья в общеобразовательной школе? & 91,5 & 8,5 \\
\hline 12 & Даёт ли медицинский вуз полноценные знания о здоровом образе жизни? & 65,0 & 35,0 \\
\hline 13 & Нужен ли в учебном плане медвуза курс здорового образа жизни? & 67,0 & 33,0 \\
\hline
\end{tabular}

Создание Д.И.Менделеевым Палаты мер и весов (1893) базировалось на принципе: «наука начинается там, где появляются измерения». В медицине использование этого принципа не всегда удаётся. В частности, измерение здоровья невозможно до тех пор, пока отсутствует точное определение его сущности. Определение здоровья, содержащееся в Уставе ВОЗ, начинается с утверждения, что здоровье - это состояние... Тем не менее, непостоянство здоровья в течение жизни и даже в течение одной недели требует придирчивого отношения к термину «состояние». Мнения врачей по этому вопросу существенно разделились. Если не состояние, то, возможно - процесс? И здесь есть повод для разногласий с преобладанием отрицательных ответов. Сомнения респондентов оправданы, во-первых, тем, что возможные изменения обусловлены не одним процессом, а совокупностью процессов, а их гетерохронность исключает возможность единого измерения. Третий вопрос о свойстве организма с позиций традиционной восточной медицины мог бы дать положительный ответ: жизнеспособность. Но европейская модель медицинского образования этот критерий не рассматривает, и он в сознании современных отечественных врачей отсутствует. На вопрос, является ли здоровье ресурсом организма, у большинства респондентов интуитивно возник позитивный ответ, однако вряд ли нашлось бы обоснование ответа при необходимости дать уточнение. Возможно, был бы назван ресурс жизнеспособности.

Вопрос о допустимости взаимозамены терминов «нравственное» и «духовное» имел целью выявление мировоззренческих позиций в суждениях о здоровье и ЗОЖ. Это имеет косвенное отношение к искажению перевода на русский язык определения здоровья, данного в Уставе ВОЗ. В англоязычном оригинале речь шла о благополучии умственном (психическом), но не о духовном. До сих пор остаётся открытым вопрос о причине искажения (если не лингвистическая ошибка, то, скорее всего, идеологическая акцентуация). Большинство ответов врачей сошлось на недопустимости смешения не родственных понятий.

Разногласия в ответах на вопросы №№ $2-6$ выявили недостаточную готовность молодых врачей к рассмотрению фундаментальных проблем медицины. Это ещё раз доказало справедливость суждения, что «современная медицина нуждается в пересмотре своих теоретических основ, в серьёзном повороте в сторону представлений о здоровье как об основном критерии медицинской практики» [2, с. 9].

Возвращаясь к дефиниции здоровья, представленной в Уставе ВОЗ, следует ещё раз обратиться к термину «полное благополучие». Если оно неполное, следовательно, здоровья нет (?), но полное отсутствие здоровья - это смерть. Об этом в анкете вопрос не стоял, так как в медицинской литературе неоднократно обсуждался термин «благополучие». «Полное физическое, умственное (или духовное?) и социальное благополучие» можно расценивать как счастье [6]. Но полное счастье не гарантирует полного здоровья, не говоря о неполном том и другом.

Отсутствие общепризнанного точного определения здоровья человека в течение полувека потребовало тщательного анализа разрозненных попыток поиска критериев здоровья в отечественной медицинской литературе и на основе этого анализа прийти к 
начальному варианту нашего определения [4]. Этот вариант неоднократно предлагался для обсуждения в различных изданиях, но не встретил ни возражений, ни одобрений. Наверное, оптимальное решение должно прийти в результате дополнительных исследований и дискуссий, но пока целесообразно напомнить исходную позицию.

Здоровье человека - это континуум естественных состояний жизнедеятельности, характеризующийся способностью организма к адекватной саморегуляции, поддержанию гомеостаза, самосохранению и самосовершенствованию соматического и психического статуса, при оптимальном взаимодействии органов и систем, адекватном приспособлении к изменяющейся окружающей среде, использовании резервных и компенсаторных механизмов в соответствии с фенотипическими потребностями и возможностями выполнения биологических и социальных функций, в том числе, рождения и воспитания потомства. Отсутствие какого-либо из перечисленных признаков у индивида означает частичную утрату здоровья. Полная утрата здоровья несовместима с жизнью. Такое понимание здоровья разделяется другими авторами, имеющими доказательства, что биологической основой здоровья является жизнеспособность [1].

Вопросы №№ 7 и 8 во второй части анкеты были рассчитаны на выявление отношения молодых врачей к элементам профессионального сленга, камуфлирующим истинное понимание здоровья человека. Опасения о недооценке влияния культуры речи на культуру врачебного мышления частично подтвердились. Рекламные и журналистские словесные штампы для многих как туманом заслонили истину, что о здоровье можно говорить применительно только к целостному организму, а не к автономной печени и не к гоголевскому свободно гуляющему «носу». Распространённое в рекламе лекарств и в обыденной речи слово «заболевание», якобы более благозвучное чем «болезнь», потеряло свой изначальный смысл как всего лишь начало болезни. Это лишь один из примеров в пользу культуры речи врача.

Вопрос, относящийся к рекламе лекарств и медицинской техники, нацелен на понимание врачом разницы между коммерцией и медициной и между ориентацией пациента на некомпетентное самолечение и оказанием квалифицированной медицинской помощи. Реклама лечебных средств не нужна ни пациенту, ни врачу. Кстати, ещё один вопрос для размышлений о здоровье: идентичны ли привычные понятия - «излечение» и «выздоровление»?

Десятый вопрос о роли медицинских знаний в выборе образа жизни дал почти с равной вероятностью положительные и отрицательные ответы, потому что многолетние попытки пропаганды ЗОЖ оказались малоэффективными. В дополнение к знаниям необходимы средства воспитательной работы по формированию мотивации, в том числе, и в процессе подготовки врачей и среднего медицинского персонала. Этой цели были подчинены последние три вопроса, которые, несмотря на преобладание положительных ответов, высветили различия в убеждённости и практической ориентации молодых врачей. В частности, неуверенность отразилась и в противоречивости ответов на два последних вопроса. Если вуз даёт полноценные знания о ЗОЖ, то вряд ли необходимо дополнительное введение в учебный план курса ЗОЖ. Если такая необходимость есть, то сомнительна полноценность ныне получаемых знаний.

\section{Выводы}

1. У большинства молодых врачей преобладает высокая оценка собственного здоровья и устойчивости к стрессу.

2. Образ жизни значительной части респондентов нельзя признать благоприятным для здоровья.

3. Выявлена неспособность большинства врачей отказаться от факторов риска и неумение использовать в полной мере факторы, полезные для здоровья.

4. Следует признать не вполне удовлетворительными знания о сущности здоровья и здорового образа жизни, получаемые в медицинских вузах. 
5. Большинство молодых врачей считает, что в учебном плане медицинского вуза нужен курс здорового образа жизни.

$$
* * *
$$

1. Булич Э. Г. Здоровье человека: биологическая основа жизнедеятельности и двигательная активность в её стимуляции / Э. Г. Булич, И. В. Муравов. - Киев: Олимпийская литература, 2003. - 424 с.

2. Григорьев А. И Концепция здоровья и проблема нормы в космической медицине / А. И. Григорьев, Р. М. Баевский. - М.: Фирма «Слово», 2001. - 96 с.

3. Давыдовский И. В. Проблема причинности в медицине: Этиология / И.В. Давыдовский. - М.: Медгиз, 1962. - $176 \mathrm{c}$.

4. Колбанов В. В. Валеология: основные понятия, термины и определения /В. В. Колбанов. - СПб.: Изд-во ДЕАН, 2001. - $256 \mathrm{c}$.

5. Щедрина А. Г. Онтогенез и теория здоровья: методологические аспекты / А. Г.Щедрина. Новосибирск: СО РАМН, 2003. - 164 с.

6. Saracci R. The World Health Organisation needs to reconsider its definition of health // British Medical Journal. - 1997. Vol. 314, 10 May. - P. 1409-1410.

7. World Health Organisation. Basic documents. 39th ed. Geneva: WHO, 1996. - 182 p.

Тимофеев Д.А. ${ }^{1}$, Цвигайло М.А. ${ }^{2}$, Раздевилова О.П. ${ }^{1}$, Власова М.В. ${ }^{1}$ Проявление глубинной мотивации в деятельности различных профессиональных групп личного состава военно-медицинской организации

${ }^{1}$ ФГБОУ ВО «Саратовский ГМУ им. В.И. Разумовского» Минздрава России (Россия, Саратов)

${ }^{2}$ Филиал №2 ФГКУ «442 ВКГ» Министерства Обороны РФ

(Россия, Псков)

doi: $10.18411 / l j-28-02-2018-62$

idsp: 000001:lj-28-02-2018-62

\section{Аннотация}

Представлены результаты исследования оценки проявления глубинной мотивации у представителей различных профессиональных групп военно-медицинской организации.

Ключевые слова: общественное здоровье и здравоохранение, управление персоналом, трудовая мотивация, глубинная мотивация.

Особенности работы организаций системы военного здравоохранения $[2,3,4,9,10]$ включают высокую детерминированность качества и эффективности их функционирования уровнем трудовой мотивации $[1,5,6,8]$, который, в свою очередь существенно зависит от привлекательности выполняемой персоналом военномедицинских организаций профессиональной деятельности (степени проявления глубинной мотивации работы) $[5,7,11]$.

Цель исследования: на основе использования «Модели характеристик работы» Р. Хэкмана и Г. Олдхэма, определить уровень проявления глубинной мотивации работы у различных профессиональных групп персонала военно-медицинской организации.

Методы. Проведено сплошное анонимное анкетирование603 человек - из числа персонала 6 госпиталей МО РФ, распределенных на профессиональные группы: «Администрация»; «Специалисты»; «Средний медицинский персонал»; «Другие» и «Младший медицинский персонал». Ответы на вопросы анкеты оценивались по 7балльной шкалеи включали пять универсальных ключевых составляющих (КС), на основе которых рассчитывался обобщенный показатель проявления в деятельности величины глубинной мотивации -«Показатель потенциала мотивации». При статистической обработке данных использован пакет прикладных программ «Statistica-10», применялся критерий Краскела-Уоллиса, попарное сравнение проводилось с использованием критерия Колмогорова-Смирнова, корреляционный анализ с помощью $\tau$-критерия Кендалла.

Результаты исследования представлены в таблице. 